\title{
MONITORING LANGUAGE LABORATORY WORK
}

\section{Introduction}

Barely six years after the establishment of the first language laboratory at the University of Utah and five years after a similar language lab had been introduced at Ohio State University, E.H. Schneck complained that students who were supposed to stamp time-slips as evidence of their attendance "(got) someone else to stamp a time-slip; or a student might stamp one when entering, leave the laboratory, and come back to stamp it several hours later" (1930:31).

Fifty years later we still seem to be stuck with the same problem. So much has been written about learner responsibility and so often have we exhorted students to come to the lab "for their own good". and yet lab attendance remains reluctant to say the least.

But how much of this reluctance is due to the attitude of those who have to monitor the student's attendance and progress? Once the roll has been called and previous absentees reprimanded, the monitor switches the tape on and the volume in his or her earphones off. The students repeat mechanically, barely awake, while the monitor catches up on his or her marking or tunes in every now and then to see whether everybody is, at least, repeating.

Motivation has always been difficult to maintain and in this essay $I$ would like to suggest a few ways of improving lab work and procedure in general, which may in turn, revitalize motivation.

\section{The teacher/lecturer as monitor}

Generally speaking the way in which we see the monitor is directly related to the modern idea of what a language teacher should be. Right from the beginning the virtue of the language laboratory has been the fact that it takes over the time-consuming and enervating task of drilling linguistic and phonetic patterns, which frees the teacher to do more creative and communicative work in class.

This has led to two assumptions: Firstly that the student should take some of the responsibility for his learning by attending lab sessions outside class time, and secondly that the work of "drilling" can 
safely be left in the care of electronic equipment and at the most a technical assistant.

The first assumption is valid only if students have been trained since high school to take some responsibility for their own learning. It is a sad fact, however, that most students have to be taught to do this only at university level.

The second assumption has led to the idea that language laboratory work is of secondary importance compared to classwork, and can easily be left in the hands of a technician or lab assistant. Not that these people are of secondary importance, but teachers seem to shove their responsibility as regards time-table planning, rewriting of material, handling student queries and monitoring too easily onto the already overburdened lab assistant.

In his article The Role of the Monitor in the Language Laboratory, H.E. Probyn criticizes this attitude towards language lab work, and indicates the consequences:

"Unfortunately in many cases an inadequate grasp of the sounder view - that of the complementary functions of the teacher and the lab. - has led to the relegation of the lab. to a passive role not unlike that of the reading-room of a library" (1966:137).

The exact way in which the lab is to complemen: classwork and the decision about the amount of time to be spent in the lab will be determined by the aims and objectives of the different courses and it is not the purpose of this essay to argue that point. What is important, though, is that the lab course be planned in context and with full and constant reference to the total course.

Edward Stack stresses the strong relationship between classroom and lab:

"Before going to the lab. for the next tape lesson, students must be informed precisely what is to be learned, how it is to be accomplished, and what the utterances mean. Definite objectives, means and comprehension provide a feeling of security and subsequent accomplishment that adds much to student motivation. The teacher must also provide conspicuous proof that laboratory work is essential to classwork" (1971:184 - 5). 
Implementing this basic precept, which needn't even take five minutes of class time, will go a long way towards eliminating the notion that the language lab periods are "extra" or merely "additional". If the student gets the vaguest idea that language lab work is inferior or of secondary importance, we might as well close its doors.

To strenghten this all-important link between classroom and lab the continued presence of the classroom teacher in the lab during the attendance of his or her own classes, is of paramount importance. A lab technician or assistant inevitably breaks the continuity with classroom work. An alternative would be to give the assistant a few notes on the content of the foregoing class, the way in which the lab is to complement that class and which problems are likely to arise. In our present circumstances this hardly seems practicable. The teacher himself remains the most important link mainly because he alone can reinforce, by his mere presence, the mental image that the lab is but an extension of the classroom.

Probyn stresses this point exactly when he warns that "the teacher who knows little or nothing of what his students are doing for as much as half the time they are under his charge cannot hope to retain in the lab the sort of trust and confidence that are built up in the classroom, and inevitably the classroom periods are adversely affected by the breakdown of this confidence" (1966:141).

Just as important as this is the fact that only by being present and actively listening, can the teacher-monitor detect weaknesses in the material presented. When listening to students doing exercises, one quickly realises that eg. certain pauses may be too short or too long. Inconsistencies on the master tape as regards pronunciation or linguistic structure pass unnoticed if one is never present to hear these tapes in practice.

Moreover, research has indicated that some exercises are much more effective when a few seconds are given for thinking, and an answer the required on the cue "Now, answer 2.1" . This type of ongoing research and the changing nee.ls of students require the constant revision of tapes by the teacher himself.

CI MEREDITH, R.A. 1978. Improved oral test scores through delayed response. Modarn Languago Journol, 62(7): $321-7$ 
The link with the classroom can further be strenghtened by requiring written preparation for certain lab classes or written work during others. A discussion of written work (with or without it having been marked) in subsequent classes once again stresses the importance of lab work.

\section{Active monitoring}

Most language labs have a "listening-in" facility for the monitor. According to Stack, this enables the monitor to correct errors in procedure firstly, linguistic errors secondly and thirdly, to evaluate (1971:6). He also gives criteria for grading student responses, concentrating on the second phase of a four-phase drill. However, these methods are, for this essay, less important than the asumption that lab work should be evaluated regularly. This is not only to force students to attend (although this usually seems to be the only way by which to blackmail them into attending!) but also to determine common errors, areas of difficulty and individual problems. Of course the question of grading or evaluation also depends on the type of material presented in a lab period.

The two audio-active-comparative labs in our Faculty of Arts each has twenty-four booths at the moment. According to a report published by Scottish educational authorities the largest group that can effectively be monitored in one period consists of no more than twenty students (quoted by Green, 1975:36). It is obvious then that a full lab cannot be evaluated in one period. It should not be too difficult, though, to grade half of the class in one period and the rest in another lab period.

More important than grading, however, is consistent monitoring to prevent mistakes, especially as regards pronunciation, being "practised". If the monitor is only interested in random "eavesdropping" to make sure that everybody is participating, students may repeat errors and will show no improvement, no matter how highly motivated they are.

It is general practice to make students listen to their own recordings. This is the most active time for the monitor. Although the students may have been in a lockstep-type of drill, the monitor can now ask a student to rewind, repeat, try and try again. All machines can be stopped if a mistake is general. Parts of a difficult tape may be repeated after clarifying comments by the monitor. 
Probyn suggests that when individual progress is being monitored the general performance of the group also be taken into account, as not all lab sessions are equally difficult or easy (1966:140). He also maintains that the monitor should not only listen, but also be in constant visual contact with his students (141). While the monitor is listening to one student he may be able to determine the depth of concentration or degree of difficulty by watching the whole class.

No monitor should hesitate to interrupt a lab session if it is obvious that group therapy may bridge a current difficulty (Hilton, 1964:49). Once more it can be seen why it is so vitally important that the teacher himself is present as the monitor. He is seen to be "squarely in the driving-seat all the time, and the class is aware that the teacher is ready to 'ad-lib' if their performance requires it" (Probyn, 1966:141).

\section{Conclusion}

Many teachers are disillusioned with the lab and perhaps only use it "because it's there." Without defending the lab or stressing its obvious good points, I would like to suggest that a lot of this disillusionment is due to simple boredom. Rigid procedures and allocation of work make lab periods predictable and inflexible.

One doesn't realize that the lab needn't only be used for grammar and pronunciation, or that continuous drilling is not the only method by which to teach these. A variety of material, of voices on the master tape, incorporating music, advertisements, short stories, poetry and dialogues between native speakers of foreign or second languages will all serve to maintain a high level of motivation. The student will not only be developing linguistic or phonetic ability but listening, reading and writing skills as well.

Throughout the year the teacher gets to know his students and vice versa. The level of enthusiasm is directly communicated from the one to the other. If lab work and the monitoring thereof is to be effective, the teacher has to feel good and optimistic about it. $\mathrm{He} / \mathrm{she}$ has to see the purpose of lab work and its immediate link with classwork. Only then will students regard it as serious and valid work, and obtain the positive results such an approach must yield. 
5. Bibliography

GREEN, P.S. ed. 1975.

The Language Laboratory in School. Edinburgh: Oliver and Boyd. $242 \mathrm{p}$.

HILTON, J.B. 1964.

The Language Laboratory in School. London: Methuen. $145 \mathrm{p}$.

PROBYN, H.E. 1966.

The role of the monitor in the language laboratory. Audio-Visual Language Journal, 30 - 32, Oct.

SCHNECK, E.K. 1930.

Practical difficulties in the use of the phonetics laboratory. Modern Language Journal, 15: 30-32, Oct.

STACK, E. 1971.

The language laboratory and modern language teaching. London: Oxford University Press. $313 \mathrm{p}$. 